\title{
CPT - DR - D50 correlations of sands for liquefaction potential analysis
}

\author{
A Hakam, S Warzuqni, BM Adji, Junaidi, IF Muharani and Mardhatillah ${ }^{1}$
}

${ }^{1}$ Civil Engineering, Engineering Faculty of Andalas University, Padang, Indonesia, e-mail: ahakam@civeng.unand.ac.id

\begin{abstract}
Liquefaction assessment is the main stage in determining the potential liquefaction in a certain site. In order to assess the potential liquefaction, the values of physical and mechanical properties of the soil are very important. Two main parameters that are essentially needed to determine the liquefaction potential in a sand deposit; those are relative density and men particle size. In Indonesia, CPT is a testing method that is very practically famous and often conducted in the field. Assessment of Liquefaction Potential will be cheap and valuable by using the results of the CPT test. For this reason, this paper describes the results of conducted research to obtain the values of the relative density and mean particle size based on the outcomes of the CPT test: those are cone resistance (qc) and friction ration (Rf). The relationship between qc-Rf and Dr-D50 is accelerated by conducting a series of tests on soil samples with variations in the value of relative density and average particle size. The test results are plotted in a graph as well as in the terms of mathematical formulations to figure out for the relationship between CPT values and Dr-D50 in detail for sands. This research is very useful to assess the liquefaction potential in a particular area with very satisfying results
\end{abstract}

\section{Introduction}

The soil liquefaction potential analysis procedure using the complicated "simplified" method [1] based on a liquefaction potential factor, (PL) as well as a liquefaction resistance factor (FL) have been proposed in 1981 [2]. The procedure has introduced the factor FL and PL. Both factors are the liquefaction potential at a certain calculated depth and at the ground surface respectively. The PL value then is famous with the name of liquefaction potential index (LPI). That factor has been used by researchers in Korea, India and Bangladesh [3] [4] [5]. The LPI indicates the damage level at the ground surface at the site of interest. This value relates to the factors of safety for liquefaction potential at the deeper point underneath.

The LPI was originally introduced for $20 \mathrm{~m}$ of depth only with the formulation of:

$L P I=\int_{0}^{20} F(z) W(z) d z$

where $\mathrm{F}(\mathrm{z})=1$ - FS with the minimum $0.0, \mathrm{~W}(\mathrm{z})$ $=10-1 / 2 \mathrm{z}$ with the minimum $0.0, \mathrm{z}$ and $\mathrm{dz}$ are the depth the incremental depth respectively.
The modified formulation of severity level of LPI has also been recommended by the other researcher [Luna 1995] as:

$\mathrm{LPI}=\sum_{i=1}^{\mathrm{n}} \mathrm{F} i \mathrm{~W} i \mathrm{H} i$

here $\mathrm{n}$ denotes the number of soil layers, $\mathrm{H} i$ denotes the thickness of the soil layer, W $i$ weighting function and $\mathrm{F} i$ is the liquefaction severity for layer $i$.

The liquefaction severity assessed based on the liquefaction potential index (LPI) for several researcher is presented in Table 1.

Table 1 The liquefaction severity - potential index

\begin{tabular}{cccc}
\hline LPI & Iwasaki [2] & $\begin{array}{c}\text { Luna-Forest } \\
{[6]}\end{array}$ & $\begin{array}{c}\text { Chung et al } \\
{[7]}\end{array}$ \\
\hline 0 & Very Low & Little to None & None \\
$0-5$ & Low & Minor & Little to None \\
$5-15$ & High & Moderate & Moderate \\
.16 & Very High & Major & Severe \\
\hline
\end{tabular}

The typical illustrations of LPI in the field bas been shown based on field observations in the New 
Zealand are presented in Fig. 1 [8]. Using the given images, the severity liquefaction can be clearly related to the liquefaction potential index (LPI) as shown in Fig. 1.

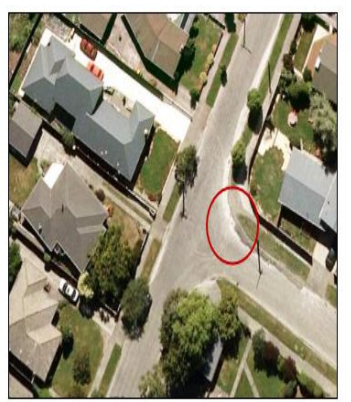

Marginal Liquefaction

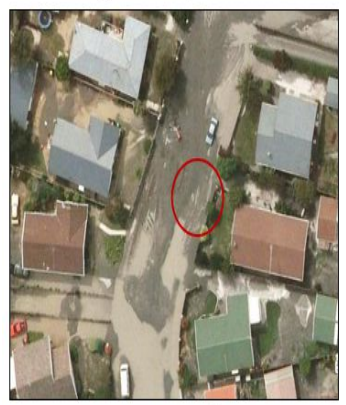

Severe Liquefaction
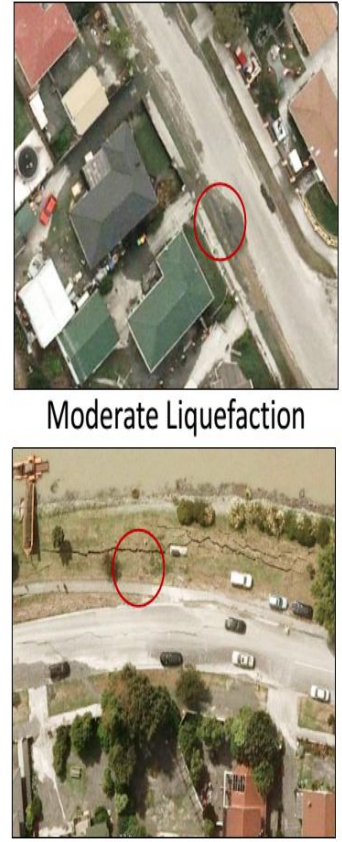

Severe Lateral Spreading
Fig. 1 Bird-eye observed liquefaction [8]

In this paper, the descriptions of liquefaction potential is focused on Field CPT test result base and the Correlations CPT (qc) to Dr and D50 of sands is presented. The correlation is developed by adopting result for past researcher's result from references.

\section{Cpt for liquefaction assessment}

The assessment of liquefaction potential is an important aspect for mapping the earthquake related hazard for certain area. The Niigata earthquake in 1964 becomes the important history for liquefaction analysis method. After the Niigata earthquake, the simplified method [1] has been introduced and then widely used by many researchers. But this method needs continuously improvement. Thus the improved simplified method became more complex. The latest version of that method involves many parameters that rarely used in geotechnical engineering and not as simple as it was named at first [10] [11].

The method also has been modified for assessing liquefaction potential based on Cone Penetration Test (CPT) results [12]. The CPT is very famous to be used in many countries, including Indonesia. The reasons are the CPT equipments are handy and not heavy. The CPT tools can be carried by at least 3 persons in the field. The operation of CPT is also relatively easy. The short training for some hours only may be needed to operate the CPT test. Using CPT test result and its correlation to relative density and size of soil grain, the liquefaction potential assessment can be developed.

The numerical cheaper of liquefaction potential in the soil layer can be done based on the mean grain size $\left(\mathrm{D}_{50}\right)$ and its relative density $(\mathrm{Dr})$ [13]. The liquefaction potential at certain depth in the soil layer may be determined by plotting those values (the relative density and the average grain size) in to the Fig. 2. The application of this method has been proven to many real cases in the fields and gave very good results [14].

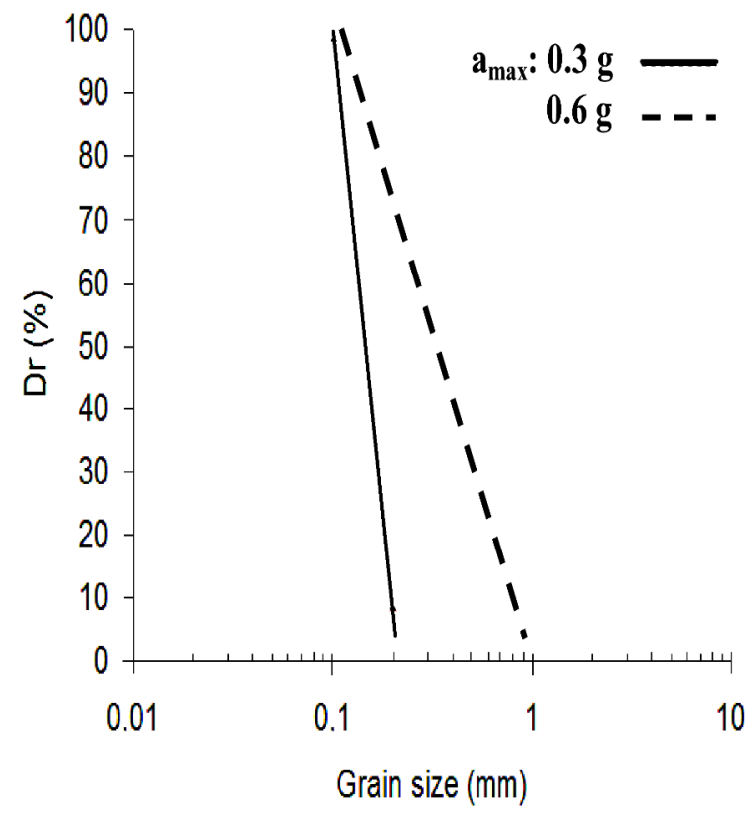

Fig. $2 \mathrm{Dr}-\mathrm{D}_{50}$ for liquefaction assessment

Based on the authors' experience so far, the most popular direct in field tests used in Indonesia is Cone Penetration Test (CPT). Even recently the use of the Standard Penetration Test (SPT) also has been regularly introduced, specifically for heavy structures. The important parameters from Cone Penetration Test are cone tip resistance parameters (qc) and sleeve resistance (qs). However, the sleeve resistance usually is compared by the tip resistance in terms of friction ratio (Fr). The both tip resistance and friction ratio of CPT tests have been used to gain the other parameters for liquefaction analysis.

Since CPT test does not produce relative density value. Then in order to develop a general method for using $\mathrm{Dr}$ and $\mathrm{D}_{50}$ liquefaction assessment, it need next step before liquefaction assessment can be done. The next step will be elaborated in the simple procedure in the next section to obtain the relative density estimation based on the correlation of those filed tests. It is also included an estimated mean of grain size procedure based on those filed tests' results. 


\section{CPT test correlation}

In order to gain the soil parameters for soil sample, it generally requires a series of laboratory tests that takes time and cost. Luckily the past engineers and researchers have done a number of precious works to obtain soil parameters from correlation soil parameter to the field test results. This approach is taken in this study to correlate soil parameters with based on the results of the most commonly used soil field investigation CPT. The correlation of CPT test results also has been proposed by many researcher as recently it is done [15].

\subsection{Dr from CPT}

The earliest relative density, Dr correlation from CPT cone resistance, qc was proposed in 1975 [16]. The Dr - qc relationship then was updated and published in 1978 [17]. Those correlations are shown in Fig. 3. It has been well known that the qc is effected by sand density, in-situ effective stress and sand compressibility. Sand compressibility depends on grain size, grain shape and mineralogy. For the liquefaction potential analysis purpose, the relative density of the soil can be taken from the cone resistant correlation in the equation as follows [18]. The Dr-qc correlations has taken into account the effect of soil mass in terms of vertical effective stress, $\sigma v^{\prime}$.

The mathematical formulation of the relative density correlation also has been suggested as follows:

$D r=C_{2}{ }^{(-1)} \ln Q / C_{0}$

Where $C_{0}=15.7, C_{2}=2.41$ and $Q=\left(q c / p_{a}\right) /\left(\sigma v^{\prime} / p_{a}\right)$

0.5. with $p_{a}$ is reference pressure taken as $100 \mathrm{kPa}$, in

the same unit as qc and $\sigma \mathrm{v}$ '.

The liquefaction assessment of sand deposit in Pasir Jambak due to Padang earthquake 2009 using that formula has been demonstrated [10]. It is found that this formulation is practically simple and gave good performance to estimate the liquefaction potential in sand deposits.

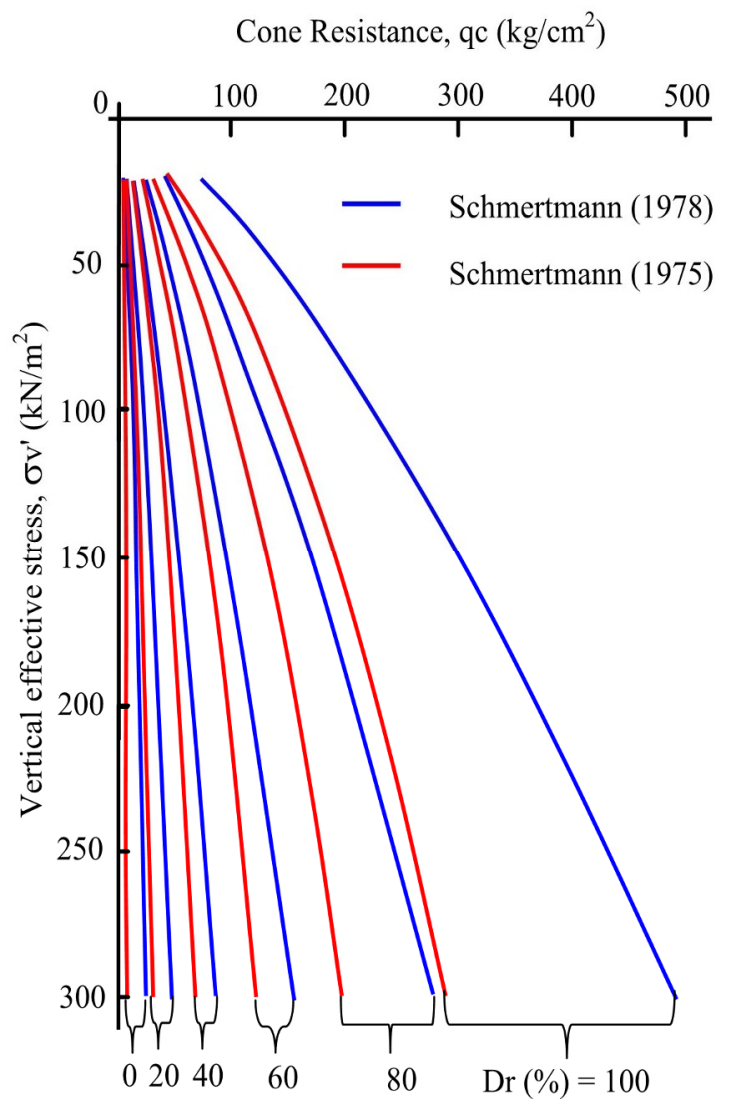

Fig. 3 Relative density - qc relationships for sandy soil, reconstructed from [17]

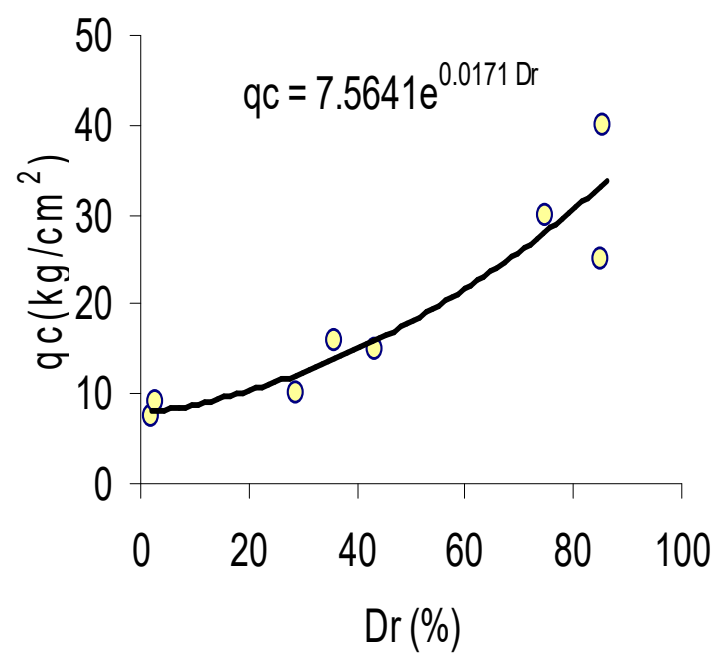

Fig. 4 Relative density - qc relationships for near surface soil 
The relative density, Dr and cone resistance, qc correlation is has been tested in laboratory as shown in Fig.4. That graph can be used for the Dr-qc correlations of near surface soil.

\subsection{D50 from CPT}

Even though it is widely used for soil investigation works in Indonesia, but CPT is rarely followed by drilling. Then the CPT test will not accompanied by soil sampling. Further the test of the grain size of the soil is not possible. But fortunately CPT also provides information on the sleeve resistance. The skin resistance compared to the tip resistance, qc is resulting in the value of Fr.

Based on those values, the CPT test results then can be used to form soil profiling as well as soil type. In sands generally the sleeve resistance is generally lower than in clays. Then, the friction ratio, Fr consequently is lower in sands and higher in clays. The Fr value can not to provide exact estimation of grain size. The Fr can provide a prediction to the soil type together with its characteristic and behavior.

In the past, many researchers had observed soil grain size using CPT. They concluded that in sandy soils have higher cone resistance, qc and lower friction ratio Fr. Thos values reverse for test in clay soils [19] [20]. Based on the CPT testes in the past, the D50 and Fr correlation is the built up as shown in Fig. 5 for the CPT data were taken from mechanical and electrical cones. The terms of $\mathrm{Fr}$ in the figure is changed to Rf.

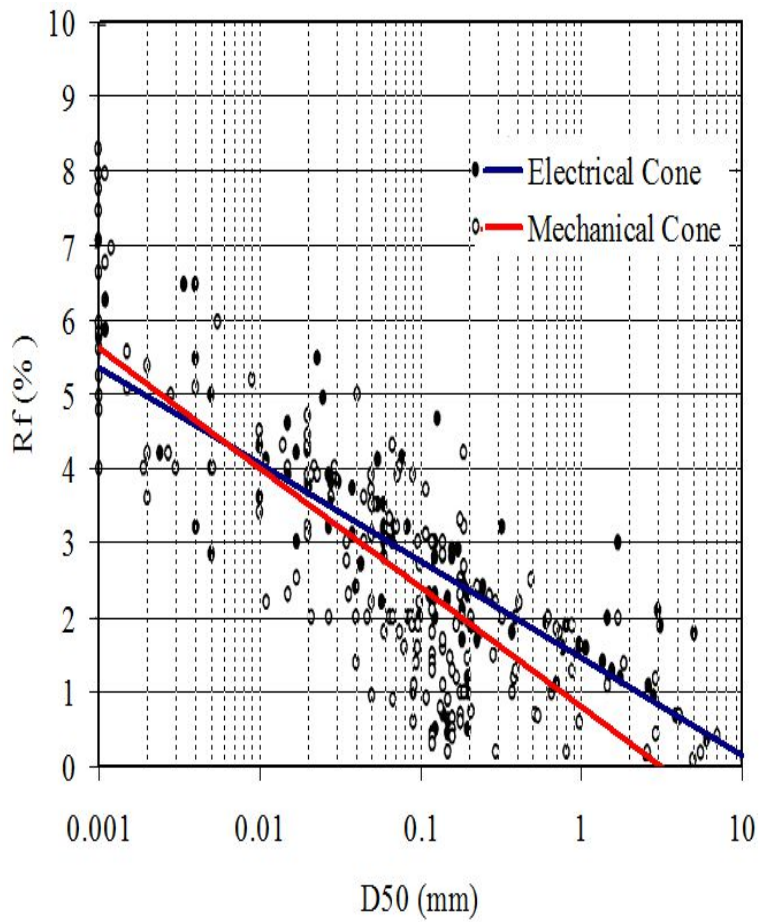

Fig. 5 Dr-Rf correlation [19]
The best fit equation for the Dr-Rf correlation has been proposed by [19] for electrical and mechanical cone as:

$\mathrm{Rf}=1.45-1.3 \log (\mathrm{D} 50)$ for electrical cone

and,

$\mathrm{Rf}=0.78-1.61 \log (\mathrm{D} 50)$ for mechanical cone

For better enstimation the value of D50 from Rf, the Eq. (5) and Eq. (6) may be turned into Eq. (7) and Eq. (8) as follows:

$\mathrm{D} 50=3.056 \mathrm{e}^{-1.4302 \mathrm{Rf}}$ for electrical cone

and respectively,

D50 $=3.0781 \times \mathrm{e}^{-(1.4327 . \mathrm{Rf})}$ for mechanical cone (8)

The mean grain size, D50 and friction ratio, $\mathrm{Rf}$ correlation is has been tested in this study as shown in Fig.6. That graph can be used for the Dr-qc correlations of near surface soil.

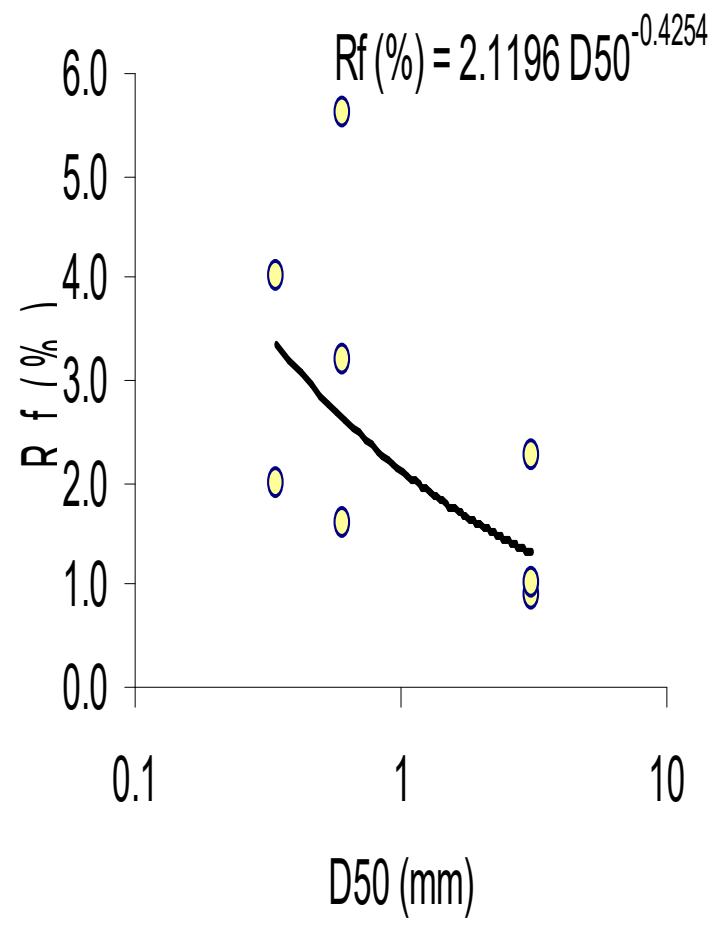

Fig. 6 Dr-Rf correlation from laboratory tests

If the SPT test is also conducted, the additional studies on soil grain size distribution had been conducted using SPT and CPT resistances [20] and [21]. The value of SPT data is presented in the terms of N60 values, The N60 value is corresponded to the energy ratio of about $60 \%$. The studied had concluded that the qc-N ratio is strongly related to the soil grain size and expressed by the mean grain size (D50) as shown in Fig.7. The study results are very useful in practical works for both CPT and SPT type of soil investigation 


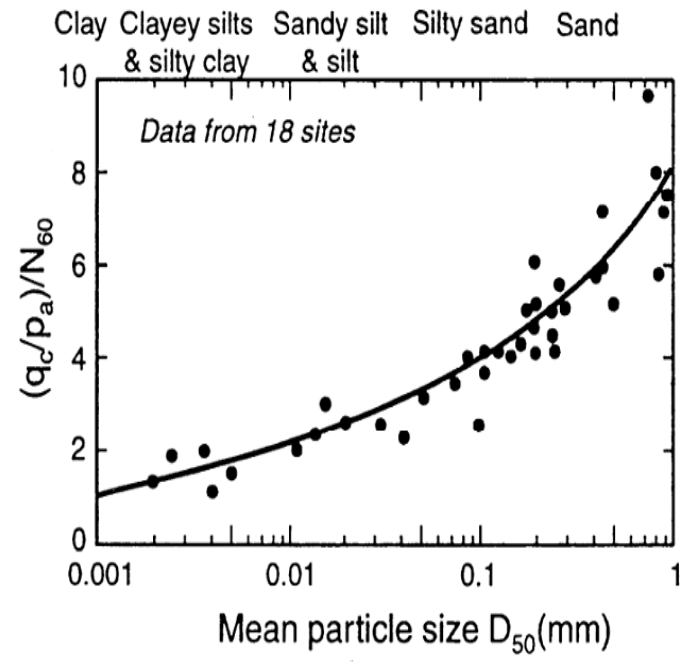

Fig. 7 CPT-SPT correlation with D50 [21]

\section{Cpt based procdure development}

Based on the previous sections description, the procedure for liquefaction potential assessment of soil layers based on CPT can be developed. The CPT based assessment is then linked to the Dr-D50 graph. The parameters obtained basically taken from the correlation of the CPT test results from field soil investigation. The Cone penetration test procedure can be made in the form of a flow chart as shown in Fig. 8. Unlikely to SPT testing, for CPT test procedure the soil samples from the soil layer must not be taken. It is not necessarily conducting sample test to determine the grain size of the soil. So the one of benefit of CPT procedure, it must not be companied by boring or sampling job to determine the soil grains.

\section{Conclusions}

In order to produce a liquefaction hazard map of a specific area, the assessment of liquefaction potential is very important and become the main step. Some liquefaction potential assessment methods have been proposed by researchers since the last century. Every method is developed based on the purposes and the completeness of available data. The modified method in here is based on soil relative density and mean grain size which are obtained from laboratory tests.

In this paper a modified new method that is easier and technically cheaper is proposed. The method is developed based on cone penetration test, CPT. The method is a new procedure that is more practical to be applied for general soil investigation test results. This method is associated with soil parameters that are obtained from the available correlation from soil investigation test results that turned into the relative density and mean grain size of the soil layer. This new procedure is expected to be more applicable and reliable in making liquefaction hazard maps.

The application of the purposed method has been done and the results in terms of liquefaction potential of Padang City area will be published soon.

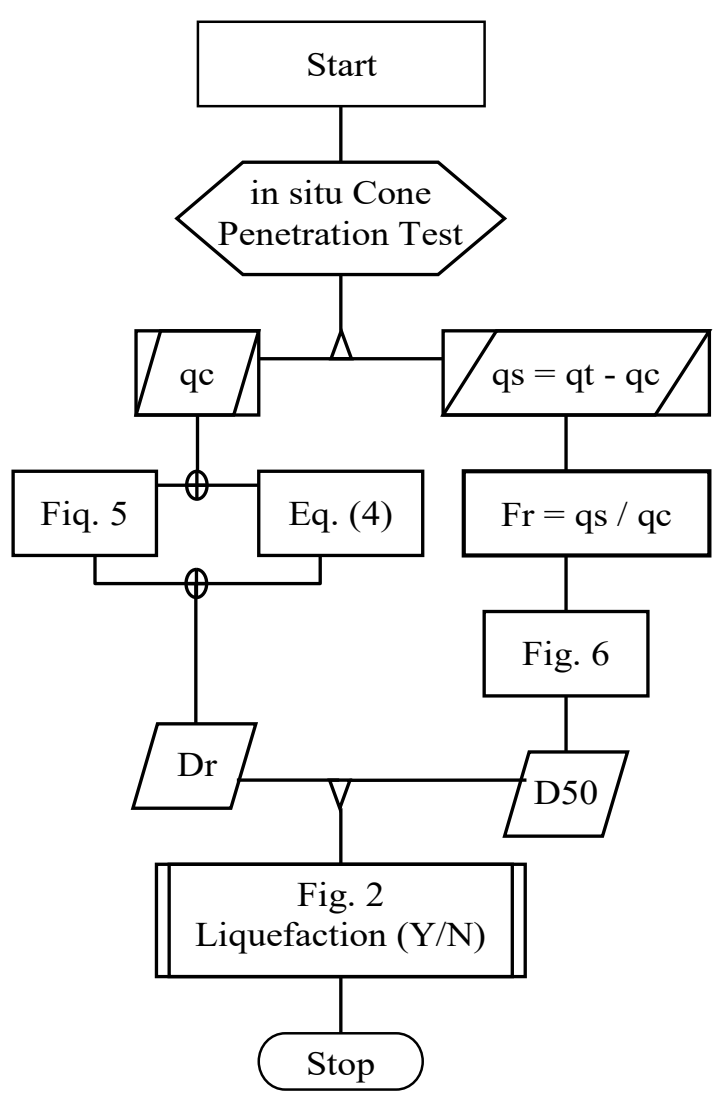

Fig. 8 Dr-D50 Procedure for CPT test results

The authors greatly express thank to Andalas University which provided any support in the process of finishing this research.

\section{References}

1. Seed H.B. and Idriss I.M., J. Soil Mech. Found Div. 97 1249-1273 (1971)

2. Iwasaki, T., Tokida, K. and Tatsuoka, F., Int. Conf. on Recent Adv. in Geotech. Earthq. Engg and Soil Dyn. 12. April 26th - May 30th, (1981)

http://scholarsmine.mst.edu/icrageesd/01icrage esd/session $02 / 12$

3. Kim H.S., Cho N.G. and Chung C.K., 15th WCEE, Lisboa 2012

4. Dixit, J., Dewaikar, D.M. and Jangid R.S., Nat. Hazards Earth Syst. Sci. 12 2759-2768, (2012)

5. Sarker D. and Ansary M.A., IOSR-JMCE 12 (2) 132-138, (2015)

6. Luna, R. and Frost, J. D., J. Comp. Civil Eng. 12 48-56 (1998) 
7. Chung, J.W. and David Rogers J., J. of Geo. and Geoenviro Eng. 137(5),505-515, (2011)

8. Maurer B.W., Green R.A., Cubrinovski M. and Bradley B.A., Evaluation of Liquefaction Potential Index (LPI) for Assessing Liquefaction Hazard: A Case Study in Christchurch, New Zealand, Poster UC, Christchurch, NZ, https://core.ac.uk/ download/ pdf/35471699.pdf (Accessed, May 2019)

9. Hakam, A., J. Eng. Technol. Sci. 48(3), 334344

10. Seed, H. Bolton dan Idriss I.M., Ground Motion and Soil Liquefaction During Earthquake, Earthquake Engineering Research Institute, Berkeley, 1982

11. Youd, T. L. and Idriss, I. M., J. Geo. and Geoenviro Engg., ASCE, 297-313, (2001)

12. Shibata, T. and Teparaksa, W., J. Soils and Foundations, 28(2), 49-60, (1998)

13. Hakam A., J. Eng. Tec. and Sc., 48(3), 334344, (2016)

14. Hakam A., Ismail F.A., Fauzan, Int. J. of GEOMATE, 11 (26) 2553-2557 (2016)
15. Urmi Z.A. and Ansary M.A, Conf. CPT18 At Netherlands, (2017)

16. Schmertmann J.H. (1975) State of the art paper: measure of in situ strength. Proceedings of ASCE Conference on in situ Measurements of Soil Properties, Raleigh, North Carolina, 57-138.

17. Schmertmann J.H. (1978), Guidelines for Cone Penetration Test, Performance and Design. Federal Highway Administration, Washington, DC, USA, 145, Report FHWA-TS-78-209.

18. Robertson P. K. and Cabal K.L., Guide to Cone Penetration Testing, GREGG inc., 2010

19. Douglas, B. J. and Olsen, R. S., Proc. of the ASCE National Convention, St. Louis, 209-27, American Society of Civil Engineers (ASCE), (1981)

20. Muromachi T. Proc. Symp. on Cone Penet. Testing and Experience, Geotech. Engg Div. ASCE, St. Louis, Missouri, 49-75, (1981)

21. Robertson, P.K., Campanella, R.G. and Wightman, A., J. of Geo. Eng., ASCE 109 (11) 1449-14, (1983) 